\title{
Detailed Chemical Kinetic Reaction Mechanisms for Incineration of Organophosphorus and Fluoro- Organophosphorus Compounds
}

\author{
P.A. Glaude, C. Melius, W.J. Pitz, C.K. Westbrook
}

This article was submitted to

$29^{\text {th }}$ International Symposium on Combustion, Sapporo, Japan, July $21-26,2002$

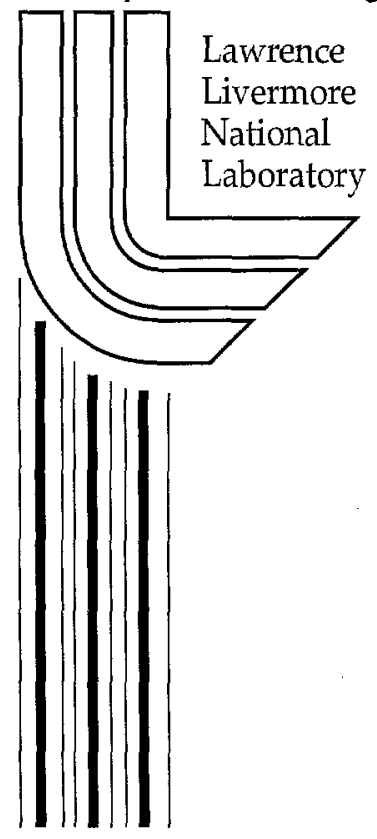

\section{December 13, 2001}




\section{DISCLAIMER}

This document was prepared as an account of work sponsored by an agency of the United States Government. Neither the United States Government nor the University of California nor any of their employees, makes any warranty, express or implied, or assumes any legal liability or responsibility for the accuracy, completeness, or usefulness of any information, apparatus, product, or process disclosed, or represents that its use would not infringe privately owned rights. Reference herein to any specific commercial product, process, or service by trade name, trademark, manufacturer, or otherwise, does not necessarily constitute or imply its endorsement, recommendation, or favoring by the United States Government or the University of California. The views and opinions of authors expressed herein do not necessarily state or reflect those of the United States Government or the University of California, and shall not be used for advertising or product endorsement purposes.

This is a preprint of a paper intended for publication in a journal or proceedings. Since changes may be made before publication, this preprint is made available with the understanding that it will not be cited or reproduced without the permission of the author.

This report has been reproduced directly from the best available copy.

Available electronically at http://www.doc.gov/bridge

Available for a processing fee to U.S. Department of Energy

And its contractors in paper from

U.S. Department of Energy

Office of Scientific and Technical Information

P.O. Box 62

Oak Ridge, TN 37831-0062

Telephone: (865) 576-8401

Facsimile: (865) 576-5728

E-mail: reports@adonis.osti.gov

Available for the sale to the public from

U.S. Department of Commerce

National Technical Information Service

5285 Port Royal Road

Springfield, VA 22161

Telephone: (800) 553-6847

Facsimile: (703) 605-6900

E-mail: orders@ntis.fedworld.gov

Online ordering: http://www.ntis.gov/ordering.htm

\section{OR}

Lawrence Livermore National Laboratory

Technical Information Department's Digital Library

http://www.llnl.gov/tid/Library.html 
Detailed Chemical Kinetic Reaction Mechanisms for Incineration
of Organophosphorus and Fluoro-Organophosphorus Compounds

\author{
P. A. Glaude \\ Département de Chime Physique des Réactions, CNRS-ENSIC \\ BP. 451, 1, rue Grandville \\ 51001 Nancy, France \\ C. Melius, W. J. Pitz, C. K. Westbrook \\ Lawrence Livermore National Laboratory \\ Livermore, CA, USA
}

Corresponding author:

Dr. Charles K. Westbrook

L-091

Lawrence Livermore National Laboratory

P. O. Box 808

Livermore, CA 94550

USA

fax: 925-422-2644

email: westbrook1@llnl.gov

colloquium choice

1. Reaction kinetics of combustion

2. Incineration

Word count

Text (Word software word count) 2654

References 35 lines $\times 7 \quad 245$

Figures (fig $1,2,3,4,7,8 \times 200$

fig $5,6 \times 400 \quad 2000$

Table 1

Total $\quad 5499$ 


\title{
Detailed Chemical Kinetic Reaction Mechanisms for Incineration of Organophosphorus and Fluoro-Organophosphorus Compounds
}

\author{
P. A. Glaude*, C. Melius, W. J. Pitz, C. K. Westbrook \\ Lawrence Livermore National Laboratory
}

\begin{abstract}
A detailed chemical kinetic reaction mechanism is developed to describe incineration of the chemical warfare nerve agent sarin (GB), based on commonly used principles of bond additivity and hierarchical reaction mechanisms. The mechanism is based on previous kinetic models of organophosphorus compounds such as TMP, DMMP and DIMP that are often used as surrogates to predict incineration of GB. Kinetic models of the three surrogates and GB are then used to predict their consumption in a perfectly stirred reactor fueled by natural gas to simulate incineration of these chemicals. Computed results indicate that DIMP is the only one of these surrogates that adequately describes combustion of GB under comparable conditions. The kinetic pathways responsible for these differences in reactivity are identified and discussed. The most important reaction in GB and DIMP that makes them more reactive than TMP or DMMP is found to be a six-center molecular elimination reaction producing propene.
\end{abstract}




\section{Introduction}

Organophosphorus compounds are used widely, from flame inhibitors and catalytic agents in aircraft turbines to common pesticides. Another class of organophosphate compounds are chemical warfare (CW) agents, and combustion chemistry of these compounds is an important theoretical and applied subject. In particular, international treaties have mandated destruction of existing chemical warfare agents, and incineration is an attractive means of accomplishing that destruction. However, uncertainties in rates of combustion, temperatures and residence times make it difficult to assure confidence in the ability to destroy these chemicals sufficiently to ensure complete safety. Extreme toxicity of CW agents makes it undesirable or impossible to carry out conventional experiments to improve understanding of their combustion chemistry.

The most common approach to dealing with these uncertainties is to carry out experimental studies with "surrogate" or "simulant" compounds whose combustion properties would be expected to be equivalent to those of the agent to be incinerated. However, little attention has been given to determining how well a given surrogate really represents the incineration behavior of the $\mathrm{CW}$ agent.

In this study, a detailed chemical kinetic reaction mechanism is developed for the CW agent, sarin (GB), to provide a new way to predict incineration behavior for real agents. Then computed results from the $\mathrm{CW}$ and surrogate reaction mechanisms are compared to evaluate how well the surrogate 
reproduces reactivity of the agent. Since computed results for surrogates can be compared directly with experimental data, this technique can test proposed agent incineration conditions that cannot be studied experimentally. Mechanism reduction techniques can also provide reduced mechanisms for multidimensional CFD models of practical incinerators.

Sarin and its common surrogates are shown in Figure 1. The most commonly used surrogate is dimethyl methyl phosphonate (DMMP), which substitutes a methoxy group for the $F$ atom and another methoxy group for the isopropoxy group in GB. Di-isopropyl methyl phosphonate (DIMP), in contrast, retains the isopropoxy group in GB and substitutes a second isopropoxy group for the $\mathrm{F}$ atom. A third surrogate species, trimethyl phosphate (TMP) is also shown.

Pyrolysis and oxidation experiments have been carried out previously in flow reactors and laminar flames, using the surrogates in Fig. 1, as well as diethyl methyl phosphonate (DEMP) and triethyl phosphonate (TEP). The flow reactor experiments at temperatures of 700-900K focused on pyrolysis of DEMP, TEP and DIMP [1-3], while flame studies [4-13] examined laminar premixed $\mathrm{H}_{2} / \mathrm{O}_{2}$ and $\mathrm{CH}_{4} / \mathrm{O}_{2}$ flames to which small amounts of organophosphorus species were added. In each of these studies, temperatures and species concentrations of important hydrocarbon and phosphorus-containing species were measured.

These experimental species and temperatures have been used to determine rates of individual reactions and to develop kinetic models for the 
pyrolysis and oxidation of many of these compounds. In particular, Zegers and Fisher [1-3] used their flow reactor experiments to provide rates of the six-center eliminations in DEMP, TEP and DIMP at 800K. Glaude et al. [14] used those values to derive rate expressions for the same reactions that could be used at higher temperatures as well. The same rate expression for the six-center elimination reaction producing propene from DIMP is used for the same reaction in $\mathrm{GB}$, with the A-factor reduced by a factor of two to reflect the fact that $G B$ has only one isopropoxy group while DIMP has two.

Glaude et al. developed a kinetic model for pyrolysis and oxidation of DEMP, TEP, DIMP, DMMP, and TMP, built upon earlier kinetic models. In addition to kinetic rate parameters, thermochemical data were developed for species containing phosphorus, including enthalpies of formation, entropies, heat capacities, and group additivity values, as well as group contributions for organophosphorus species with $\mathrm{F}$ atoms. With this analysis, pyrolysis and oxidation experiments for all of these surrogate compounds were described accurately using a single detailed kinetic mechanism.

In this work, additional thermochemical and kinetic quantities required to include the $\mathrm{P}$ - $\mathrm{F}$ bond and reactions involving the $\mathrm{F}$ atom in $\mathrm{GB}$ have been added to the previous model. The model for $G B$ and the different surrogates can then be used to describe numerical experiments in which combustion properties of the surrogates can be compared directly with those of GB. In this study, this technique is used to predict consumption of GB and its surrogates in a perfectly 
stirred reactor as an approximation to their relative rates of destruction in a natural gas-fired incinerator.

\section{Kinetic Mechanism}

This kinetic modeling effort is a good example of the use of hierarchical reaction mechanisms $[15,16]$. The base mechanism involves the $\mathrm{C} / \mathrm{H} / \mathrm{O} /$ species and reactions, which have been investigated thoroughly in kinetic modeling studies (e.g., Warnatz [17]), beginning with $\mathrm{H}_{2} / \mathrm{O}_{2}$ kinetics and adding complexity in hydrocarbon kinetics as needed. When the major fuel is $\mathrm{H}_{2}$ or $\mathrm{CH}_{4}$, and the organophosphorus additive is TMP, TEP or DMMP, the hydrocarbon submechanism can be limited to $C_{1}$ and $C_{2}$ species, and a mechanism such as GRI-Mech v. 3 [18] would be sufficient. For DIMP or GB, where the hydrocarbon side group is a propyl radical, it is necessary to include a $\mathrm{C}_{3}$ submechanism for propane to describe combustion of the isopropyl radical and the propene which will be produced. Low temperature hydrocarbon submechanisms can be included if necessary, but they were not required in the present work. The $\mathrm{C}_{3}$ reaction mechanism used is a subset of a recent modeling study of iso-octane oxidation [19]. This portion of the mechanism includes 76 chemical species and 397 elementary reactions. The organophosphate reaction system consists of the species and reactions developed previously [14] for the surrogates, which contributes an additional 63 chemical species and 274 elementary reactions. 
The remainder of the mechanism describes the reactions of GB and the additional species containing $\mathrm{F}$ atoms produced during its consumption, an additional 17 species and 75 elementary reactions. The important reactions involving GB consumption are summarized in Table 1, and the entire mechanism will be available on our Web page [see ref. 19]. $\mathrm{H}$ atom abstractions are calculated with Evans-Polanyi relationships [20] for $\mathrm{H}, \mathrm{O}, \mathrm{OH}$ and $\mathrm{CH}_{3}$ reacting with hydrocarbons, and isomerization rates are estimated considering internal $\mathrm{H}$ abstraction involving a cyclic transition state [19]. The radical $\beta$-scission decompositions are assumed to have A-factors of $2 \times 10^{13}$, with activation energies calculated from the reverse addition reactions.

The PSR code, version 6.38 was used together with the Chemkin model $[21,22]$ to study relative consumption of mixtures of natural gas, air, and small quantities $(0.1 \%$ overall) of each organophosphorus compound in Fig. 1 under idealized, stirred reactor conditions. The mixtures were stoichiometric, assuming the $\mathrm{C}$ atoms produce $\mathrm{CO}_{2}$, the $\mathrm{H}$ atoms produce $\mathrm{H}_{2} \mathrm{O}$, the $\mathrm{F}$ atoms produce $\mathrm{HF}$ and the $\mathrm{P}$ atoms produce $\mathrm{PO}[\mathrm{OH}]_{3}$, the product containing $\mathrm{P}$ predicted to be the primary product when $\mathrm{F}$ atoms are not present. The natural gas was defined for this study as a mixture of $94 \% \mathrm{CH}_{4}$ and $6 \% \mathrm{C}_{2} \mathrm{H}_{6}$. The stirred reactor was used as a system to provide insight into kinetics of incineration.

\section{Stirred Reactor Simulations}


PSR calculations were carried out for all four additives. A base case reactor was selected at a temperature of $1500 \mathrm{~K}$ with a residence time of 0.1 seconds, typical of incineration conditions. At steady-state conditions, the amounts of additive remaining are shown in Figure 2. Both GB and DIMP are consumed rapidly enough that their concentrations reach mole fractions below $10^{-9}$ under these conditions, while both DMMP and TMP are consumed at much lower rates. With inlet concentrations of $10^{-3}$ mole fraction, the GB and DIMP achieve six "nines" $\left(\mathrm{C}_{\text {consumed }} / \mathrm{C}_{\text {inlet }}>0.999999\right)$ destruction while the DMMP and TMP achieve only three "nines" (>0.999) destruction. For comparison, six "nines" destruction is required by the US Environmental Protection Agency for hazardous waste incineration of dioxins and polychlorinated biphenyls.

Results of these computations show that DIMP is a much more appropriate surrogate for sarin than DMMP or TMP under these "incineration" conditions. While DMMP and TMP have very nearly equal reactivity, they are three orders of magnitude less reactive than GB or DIMP under these conditions.

These trends continue over a range of reactor temperatures and residence times. Computational predictions of additive concentrations remaining after a residence time of 0.1 seconds at other temperatures are summarized in Figure 3, showing that DIMP and GB continue to be consumed at very nearly identical rates, while DMMP and TMP are always less reactive at similar temperatures. When the residence times are varied while keeping the reactor temperature at $1500 \mathrm{~K}$, consumption predicted for the additives is shown in Figure 
4 and suggests that GB would require a residence time of about 0.1 seconds to achieve six "nines" destruction, while DMMP would require a residence time of at least 1000 seconds.

\section{Discussion}

In all four PSR models, overall combustion kinetics are dominated by oxidation of natural gas. All four have approximately the same radical pool of $\mathrm{H}$, $\mathrm{O}, \mathrm{OH}, \mathrm{HO}_{2}, \mathrm{CH}_{3}$ and others, with consumption of methane and ethane, mainly by reactions with $\mathrm{OH}$ and $\mathrm{H}$ radicals, being very similar in each case. For example, at the conditions of Fig. 2, the methane mole fraction remaining in the reactor for both TMP and DMMP is approximately 0.00122 while the remaining level is 0.00071 in the cases of DIMP and GB, a difference of less than a factor of two, while the additive conversions are different by nearly three orders of magnitude (Fig. 2). This suggests that differences in additive consumption are not due primarily to radical levels.

The most important difference in the active kinetic pathways for these simulations is that both DIMP and GB have isopropoxyl radicals connected to the $\mathrm{P}$ atom, making it possible for transfer of an $\mathrm{H}$ atom from isopropoxy to the double-bonded $\mathrm{O}$ atom via a six-center molecular elimination reaction. As discussed previously [14], we used a rate expression for these reactions of $1 \times 10^{13} \exp (-20735 / T)$ for GB and twice that rate for DIMP with two isopropoxy radicals. Because the analogous radicals in TMP and DMMP are methoxy 
radicals rather than isopropoxy radicals, the molecular elimination reactions are four-center eliminations, with activation energies much higher than for the sixmember reactions and correspondingly much slower rates.

For this simple reason, reactions consuming TMP and DMMP are $\mathrm{H}$ atom abstractions by $\mathrm{OH}$ and $\mathrm{H}$ radicals, while six-center molecular elimination reactions in GB and DIMP producing propene molecules are much faster than any $\mathrm{H}$ atom abstraction reactions. Even the slightly greater destruction of TMP shown in Fig. 2, relative to that of DMMP, is due to the fact that TMP has three methoxy groups while DMMP has two methoxy groups and one methyl group. The greater $\mathrm{C}-\mathrm{H}$ bond strength in the phosphorus-bound methyl $(104.9 \mathrm{kcal}-\mathrm{mol}$ 1) makes $\mathrm{H}$ atom abstraction slower than from the methoxy radical, with a $\mathrm{C}-\mathrm{H}$

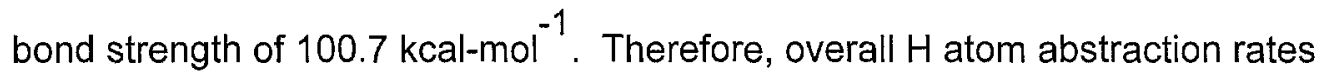
from DMMP are slightly slower than from TMP, with a slightly greater overall consumption of TMP.

Another view of the same point is provided by computed results as functions of reactor temperature in Fig. 3. Results for GB and DIMP are straight lines, with a slope determined by the activation energy of the 6-center propene elimination reactions, while results for TMP and DMMP are much more complex and can be traced to the availability of $\mathrm{OH}$ and $\mathrm{H}$ radicals to consume those additives via $\mathrm{H}$ atom abstraction.

\section{DMMP}


The oxidation pathway under these conditions was discussed by Glaude et al. [14] and is summarized in Figure 5, with only the major reactions shown. Principal reactions consuming DMMP are $\mathrm{H}$ atom abstractions from the methoxy radicals, primarily by $\mathrm{OH}$ ( $57 \%$ of DMMP consumption), with smaller contributions by $\mathrm{H}(16 \%)$ and $\mathrm{O}(3 \%)$ atoms. $\mathrm{H}$ atom abstractions from the methyl group by $\mathrm{OH}$ and $\mathrm{H}$ provide $14 \%$ of DMMP consumption, but rapid subsequent $\mathrm{H}$ atom transfer from a methoxy site to the $\mathrm{CH}_{2}$ group produces the same radical as that produced by the principal abstraction route.

In either case, the next step is elimination of formaldehyde, followed by loss of the methyl radical. At this point, the mechanism predicts that addition of water to $\mathrm{CH}_{3} \mathrm{OPO}$ produces $\mathrm{CH}_{3} \mathrm{OP}(\mathrm{OH})_{2}$ which then eliminates methanol, producing HOPO. Each step in this sequence from DMMP to HOPO consumes more than $90 \%$ of that reactant, so this is a rather uncomplicated sequence, leading to small species with $\mathrm{H}, \mathrm{O}$ and $\mathrm{P}$ atoms.

\section{TMP}

Consumption of TMP is similar to that of DMMP. The slightly greater $\mathrm{C}$ $\mathrm{H}$ bond energy in the methyl radical of DMMP leads to a very slightly greater reactivity in TMP, which has a methoxy radical at the same location in the molecule. Otherwise, the overall reaction pathways proceed primarily through the paths indicated in Figure 6. 


\section{DIMP}

As already noted above, the much larger isopropyl radicals that replace the methyls present in DMMP and TMP introduce alternative, much faster reaction channels for DIMP, as summarized in Figure 7. Elimination of propene consumes virtually $100 \%$ of the DIMP, and the resulting intermediate product decomposes via elimination of isopropanol $(66 \%)$ or a second propene $(34 \%)$ followed by elimination of $\mathrm{H}_{2} \mathrm{O}$; both sequences lead to $\mathrm{CH}_{3} \mathrm{PO}_{2}$.

GB

Consumption of GB is the simplest of all four species studied here, as shown in Figure 8. Similar to DIMP, the six-center elimination of propene is the first reaction of GB under these high temperature conditions, and this step is orders of magnitude faster than any $\mathrm{H}$ atom abstraction or other reaction of $\mathrm{GB}$. The product then reacts by means of another molecular elimination, this time producing $\mathrm{HF}$, the result of the very labile $\mathrm{H}$ atom in the $\mathrm{OH}$ group. The product of this step is $\mathrm{CH}_{3} \mathrm{PO}_{2}$, exactly as produced in the oxidation of DIMP (Fig. 7). It is interesting to note that this very rapid decomposition and removal of the $F$ atom from the original molecule suggests that the toxicity of GB is destroyed very early in its incineration, although the overall chemical contents of the reactor might take considerably longer to reach a final equilibrium composition. Further, these two initial reactions are reversible, so under some conditions GB can be 
consumed but re-created by the reverse reactions, so true destruction of GB requires the third reaction, breaking the $\mathrm{P}-\mathrm{C}$ bond.

The final composition of the material exiting the PSR is close to the equilibrium composition at $1500 \mathrm{~K}$. Approximately $95 \%$ of the $\mathrm{F}$ atoms in GB exits as $\mathrm{HF}$, with the remainder as $\mathrm{FPO}_{2}(4 \%)$ and $\mathrm{POF}(\mathrm{OH})_{2}(1 \%)$. Approximately $90 \%$ of the $\mathrm{P}$ atoms exit as $\mathrm{HOPO}_{2}$, with smaller fractions of $\mathrm{FPO}_{2}(4 \%)$ and HOPO (1\%).

\section{CONCLUSIONS}

The present study has used familiar modeling techniques to develop a detailed chemical kinetic reaction mechanism for incineration of a typical $\mathrm{CW}$ agent sarin $(\mathrm{GB})$. By combining the $\mathrm{GB}$ reaction mechanism with others developed previously for common surrogates for CW agents DMMP, TMP and DIMP, this study has demonstrated that only DIMP reproduces the predicted rate of CW agent consumption under conditions typical of incineration, while the other surrogates TMP and DMMP are consumed at very much slower rates. These differences were traced to the molecular structure of each compound, in particular the isopropoxy radical in DIMP and GB where TMP and DMMP have methoxy radicals, and the resulting molecular elimination reaction of propene in DIMP and GB that is made possible by these differences in structure.

The same kinetic modeling approach could be extended to other $\mathrm{CW}$ agents to provide guidance to incineration programs intended to destroy 
stockpiles in the future. Kinetic modeling provides a unique tool for extending experiments with surrogate compounds to real CW agents and offers the best possible means of predicting the combustion properties of these highly toxic chemicals, in the absence of actual experimental data on them.

\section{ACKNOWLEDGMENTS}

The authors thank $V$. Babushok for providing thermochemical data and $E$. Zegers and E. Fisher for their experimental data and insights. Valuable interactions with W. Tsang, J. Bozzelli and F. Gouldin are also appreciated. This work was performed under the auspices of the U.S. Department of Energy by the Lawrence Livermore National Laboratory under contract No. W-7405-ENG-48. 


\section{Figure Captions}

1. The four organophosphorus compounds TMP, DMMP, DIMP and GB.

2. Computed results for PSR model, showing residual levels of each organophosphorus additive. Inlet contains stoichiometric natural gas and air, with $0.1 \%$ additive.

3. PSR results at different reactor temperatures, same compositions as in Fig. 2.

4. PSR results at different residence times, same compositions as in Fig. 2.

5. Reaction pathways for oxidation of DMMP in high temperature PSR.

6. Reaction pathways for oxidation of TMP in high temperature PSR.

7. Reaction pathways for oxidation of DIMP in high temperature PSR.

8. Reaction pathways for oxidation of GB in high temperature PSR. 


\section{References}

1. Zegers, E.J.P., and Fisher, E.M., Combust. Sci. Technol. 116, 69-89 (1996).

2. Zegers, E.J.P., and Fisher, E.M., Combust. Sci. Technol. 138, 85-103 (1998).

3. Zegers, E.J.P., and Fisher, E.M., Combust. Flame 115, 230-240 (1998).

4. MacDonald, M.A., Jayaweera, T.M., Fisher, E.M., and Gouldin, F.C., Combust. Flame 116, 166-176 (1999).

5. Werner, J.H., and Cool, R.A., Combust. Flame 117, 78-98 (1999).

6. Korobeinichev, O.P., Ilyin, S.B., Mokrusnin, V., and Shmakov, A.G., Combust. Sci. Technol. 116, 51-67 (1996).

7. Korobeinichev, O.P., Shvartsberg, V.M., Chernov, A.A., and Mokrusnin, V., Proc. Combust. Inst. 26, 1035-1042 (1996).

8. Korobeinichev, O.P., Ilyin, S.B., Shvartsberg, V.M. and Chernov, A.A., Combust. Flame 118, 727-732 (1999).

9. Korobeinichev, O.P., Ilyin, S.B., Shvartsberg, V.M. and Chernov, A.A., Combust. Flame 118, 718-726 (1999).

10. Korobeinichev, O.P., Bolshova, T., Shvartsberg, V.M., Chernov, A.A., and Mokrusnin, $V$., in Halon Options Technical Working Conference, Albuquerque, NM, 1999, pp. 488-498.

11. Korobeinichev, O.P., llyin, S.B., Bolshova, T., Shvartsberg, V.M., and Chernov, A.A.,Combust. Flame 121, 593-609 (2000).

12. Korobeinichev, O.P., S.B., Bolshova, T., Shvartsberg, V.M., and Chernov, A.A., Combust. Flame 125, 744-751 (2001).

13. Korobeinichev, O.P., Chernov, A.A., and Bolshova, T., Combust. Flame $123,412-420(2000)$.

14. Glaude, P.A., Curran, H.J., Pitz, W.J., and Westbrook, C.K., Proc. Combust. Inst. 28, 1749-1756 (2000).

15. Westbrook, C.K., and Dryer, F.L., Proc. Combust. Inst. 18, 749-767 (1980). 
16. Westbrook, C.K., and Dryer, F.L., Prog. Energy Combust. Sci. 10, 1-57 (1984).

17. Warnatz, J., chapter 5 in "Combustion Chemistry", W. C. Gardiner, Jr., ed., Springer-Verlag, New York, 1984.

18. Frenklach, M., Wang, H., Goldenberg, M., Smith, G.P., Golden, D.M., Bowman, C.T., Hanson, R.K., Gardiner, W.C., and Lissianski, V., Gas Research Institute report GRI-95/0058; see also http://www.me.berkeley.edu/gri_mech/.

19. Curran, H.J., Gaffuri, P., Pitz, W. J., and Westbrook, C. K., submitted for publication, 2001. Mechanism is available on Web page http://www.IInl.gov/combustion/combustion_home.html

20. Dean, A. M., and Bozzelli, J.W., in Gas-Phase Combustion Chemistry, 2nd ed. (W.C. Gardiner, Jr., ed.), Springer-Verlag, New York, 1999.

21. Kee, R.J., Grcar, J.F., Smooke, M.D., and Miller, J.A., Sandia report SAND85-8240, 1985.

22. Glarborg, P., Kee, R.J., Grcar, J.F., and Miller, J.A., Sandia report SAND86-8209, 1986. 
Reaction

Molecular elimination:

pofme[oipr $]=$ pof $[\mathrm{oh}] \mathrm{me}+\mathrm{c} 3 \mathrm{~h} 6$

pof[oh]me $=\operatorname{ch} 3$ po $2+$ hf

\section{H-abstractions}

pofme[oipr] $+\mathrm{h}=$ pofme[otc3h6] $+\mathrm{h} 2$

pofme[oipr] $+h=$ pofme[opc3h6] $+h 2$

pofme[oipr] $+\mathrm{h}=$ pof[oipr][ch2]+h2

pofme[oipr] $+\mathrm{o}=$ pofme[otc $3 \mathrm{~h} 6]+\mathrm{oh}$

pofme[oipr] $+o=$ pofme[opc3h6] + oh

pofme[oipr] $+o=$ pof [oipr] [ch2] + oh

pofme[oipr] + oh $=$ pofme $[0 t c 3 h 6]+h 2 o$

pofme[oipr] $+\mathrm{oh}=$ pofme $[\mathrm{opc} 3 \mathrm{~h} 6]+\mathrm{h} 2 \mathrm{o}$

pofme[oipr] + oh $=$ pof[oipr] $[\mathrm{ch} 2]+\mathrm{h} 2 \mathrm{o}$

pofme[oipr] + ch $3=$ pofme $[$ otc3h6] + ch 4

pofme[oipr] $+\mathrm{ch} 3=$ pofme[opc3h6]+ch 4

pofme[oipr $]+\operatorname{ch} 3=\operatorname{pof}[$ oipr] $[\mathrm{ch} 2]+\operatorname{ch} 4$

pofme[oipr] + ho $2=$ pofme[otc $3 h 6]+h 202$

pofme[oipr] + ho $2=$ pofme[opc $3 \mathrm{~h} 6]+\mathrm{h} 2 \mathrm{o} 2$

pofme[oipr] + ho $2=$ pof[oipr] [ch2] + h2o 2

\section{Radical isomerizations}

pof [oipr] [ch2] = pofme[opc3h6]

pof $[$ oipr $][\mathrm{ch} 2]=$ pofme $[\mathrm{otc} 3 \mathrm{~h} 6]$

\section{Radical decompositions}

pofme[ochch 3$]=$ ch 3 cho + pofme

pofmeo $=$ fpo $2+\operatorname{ch} 3$

pofme $=$ fpo + ch 3

pofme $[$ otc $3 \mathrm{~h} 6]=$ pofme $+\operatorname{ch} 3 \operatorname{coch} 3$

pofme $[\mathrm{opc} 3 \mathrm{~h} 6]=$ pofmeo $+\mathrm{c} 3 \mathrm{~h} 6$

$\begin{array}{lll}\mathrm{A} & \mathrm{n} & \mathrm{Ea} \\ & & \\ 1.000 \mathrm{e} 13 & 0.0 & 4.120 \mathrm{e}+04 \\ 2.500 \mathrm{e} 13 & 0.0 & 5.340 \mathrm{e}+04\end{array}$

$2.400 \mathrm{e} 08$

$1.5 \quad 4.280 \mathrm{e}+03$

$1.400 \mathrm{e} 09 \quad 1.5 \quad 7.400 \mathrm{e}+03$

$\begin{array}{lll}7.200 \mathrm{e} 08 & 1.5 & 1.065 \mathrm{e}+04\end{array}$

$\begin{array}{lll}1.700 \mathrm{e} 08 & 1.5 & 2.200 \mathrm{e}+03\end{array}$

$\begin{array}{lll}1.000 \mathrm{e} 09 & 1.5 & 5.800 \mathrm{e}+03\end{array}$

$\begin{array}{lll}5.000 \mathrm{e} 08 & 1.5 & 9.475 \mathrm{e}+03\end{array}$

$1.200 \mathrm{e} 06 \quad 2.0 \quad-1.500 \mathrm{e}+03$

$\begin{array}{lll}7.200 \mathrm{e} 06 & 2.0 & 9.000 \mathrm{e}+02\end{array}$

$3.600 \mathrm{e} 06 \quad 2.0 \quad 3.450 \mathrm{e}+03$

$\begin{array}{lll}8.100 \mathrm{e} 05 & 1.87 & 7.480 \mathrm{e}+03\end{array}$

$\begin{array}{lll}4.900 \mathrm{e} 06 & 1.87 & 1.060 \mathrm{e}+04\end{array}$

$\begin{array}{lll}2.400 \mathrm{e} 06 & 1.87 & 1.736 \mathrm{e}+04\end{array}$

$\begin{array}{lll}5.000 \mathrm{e} 11 & 0.0 & 1.736 \mathrm{e}+04\end{array}$

$3.000 \mathrm{e} 12 \quad 0.0 \quad 2.110 \mathrm{e}+04$

$\begin{array}{lll}1.500 \mathrm{e} 12 & 0.0 & 2.532 \mathrm{e}+04\end{array}$

$3.000 \mathrm{e} 11 \quad 0.0 \quad 1.410 \mathrm{e}+04$

$3.000 \mathrm{e} 11 \quad 0.0 \quad 1.812 \mathrm{e}+04$

$\begin{array}{lll}2.000 \mathrm{e} 13 & 0.0 & 3.895 \mathrm{e}+04 \\ 2.000 \mathrm{e} 13 & 0.0 & 4.180 \mathrm{e}+04 \\ 2.000 \mathrm{e} 13 & 0.0 & 2.840 \mathrm{e}+04 \\ 2.000 \mathrm{e} 13 & 0.0 & 4.140 \mathrm{e}+04 \\ 2.000 \mathrm{e} 13 & 0.0 & 3.110 \mathrm{e}+04\end{array}$

Table 1 Sarin - Key Reactions 
<smiles>COP(=O)(OC)OC</smiles>

$\underline{\text { TMP }}$<smiles>CC(C)OP(C)(=O)OC(C)C</smiles>

DIMP<smiles>COP(C)(=O)OC</smiles>

$\underline{\text { DMMP }}$<smiles>CC(C)OP(C)(=O)F</smiles>

Sarin (GB)

Figure 1 


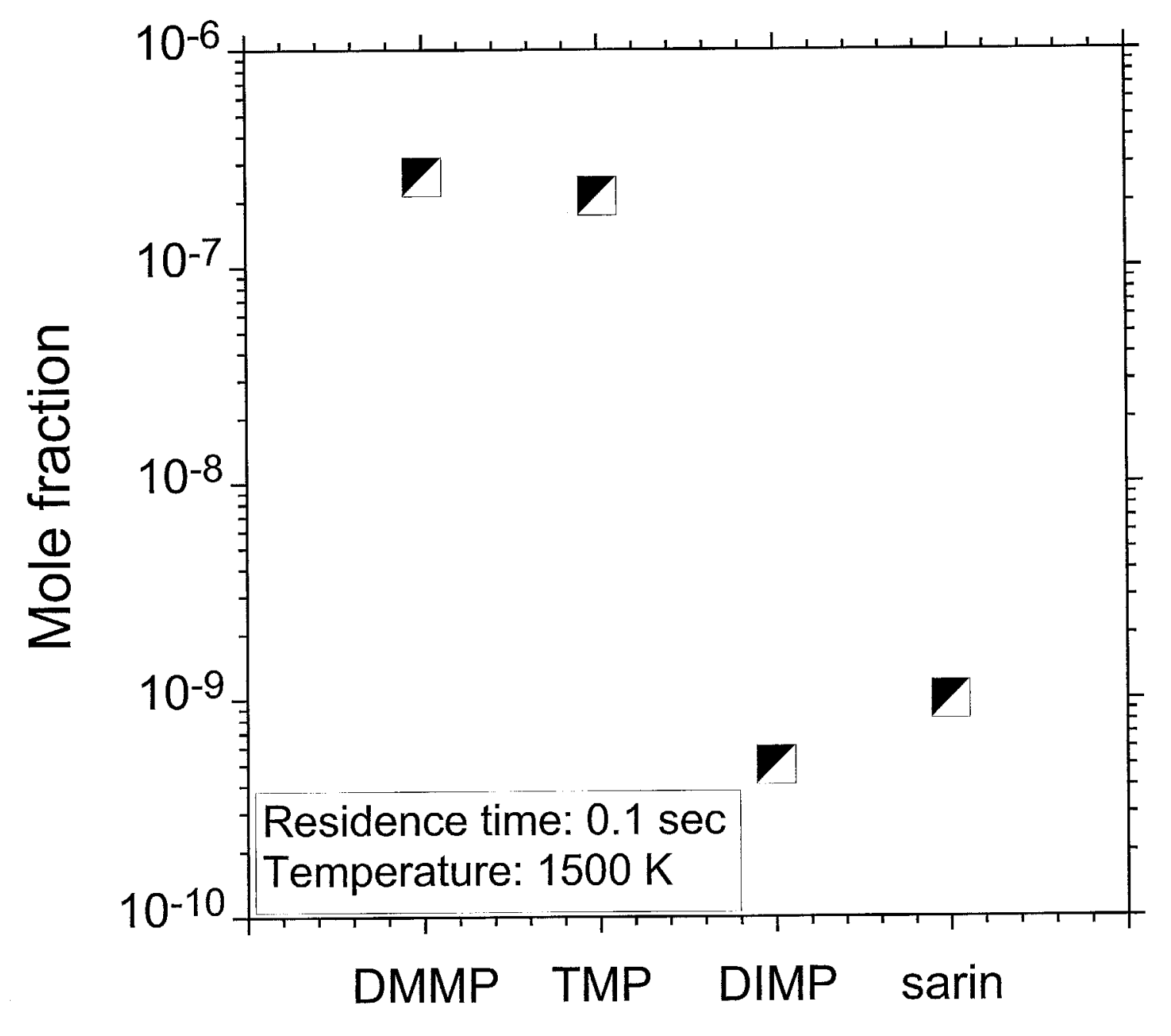

Additive

Fig. 2 


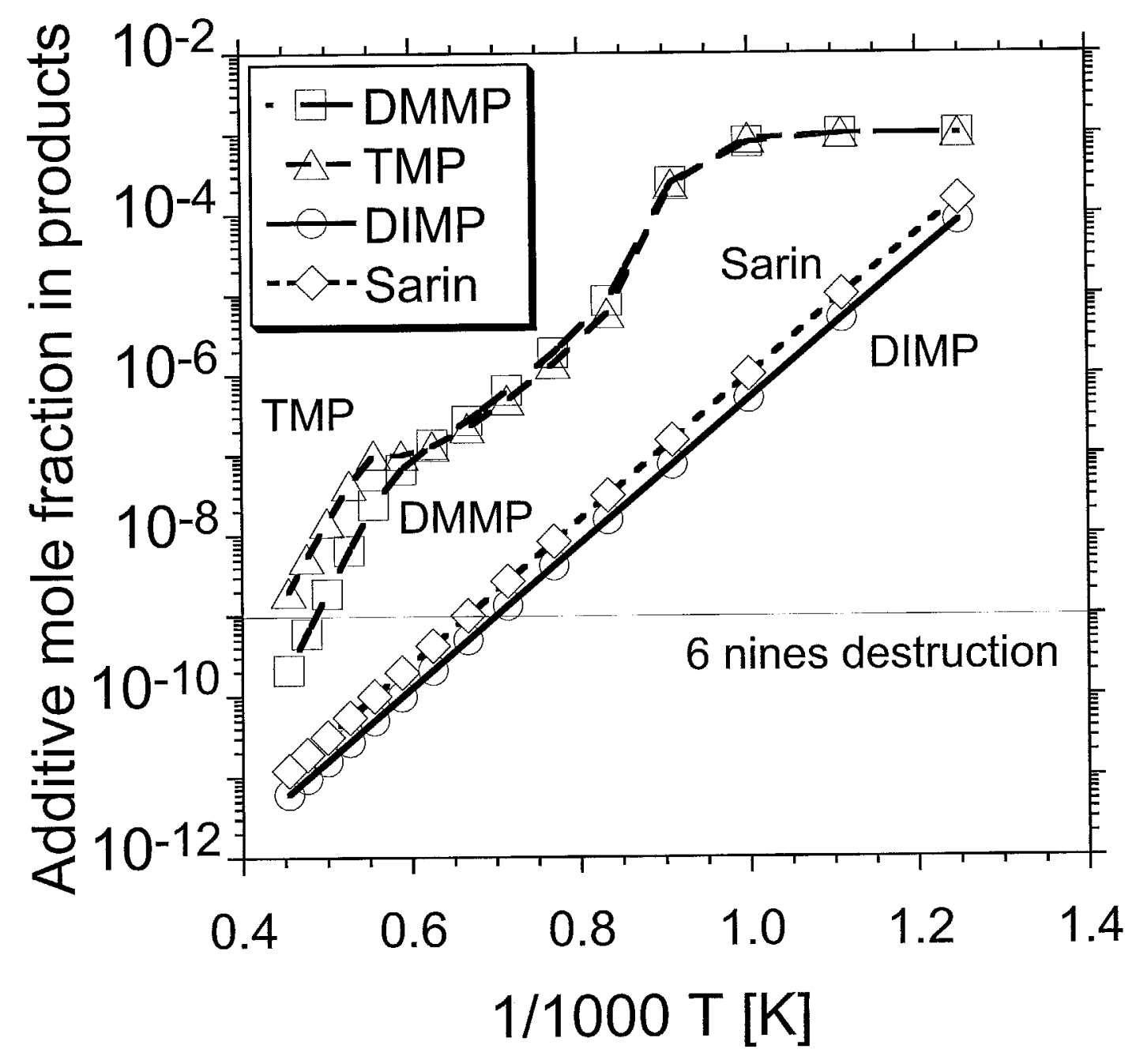

Fig. 3 


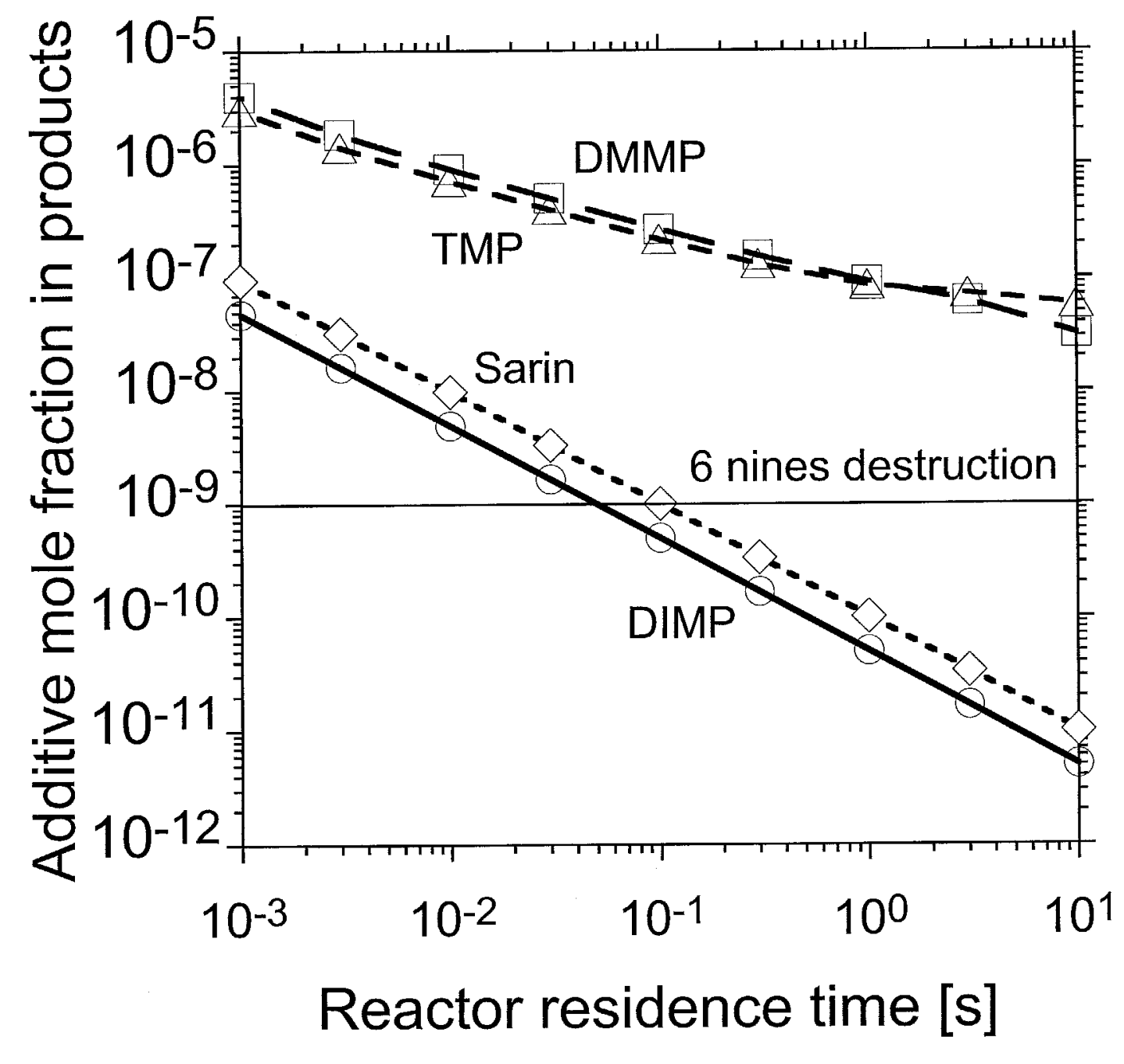

Fig. 4 
<smiles>COP(C)(=O)OC</smiles>

$\downarrow \begin{aligned} & +\mathrm{OH} \\ & +\mathrm{H}\end{aligned}$

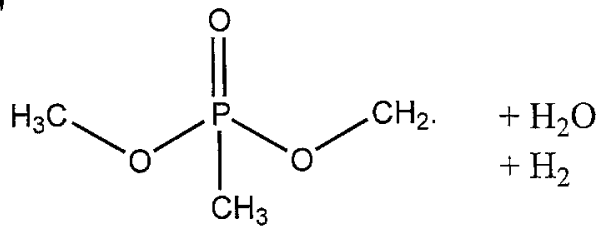<smiles>COP(C)(=O)[14CH2]CO</smiles><smiles>COP=O</smiles>

$+\mathrm{H}_{2} \mathrm{O}$<smiles>COP(O)OC</smiles>

Figure 5: DMMP reaction path 


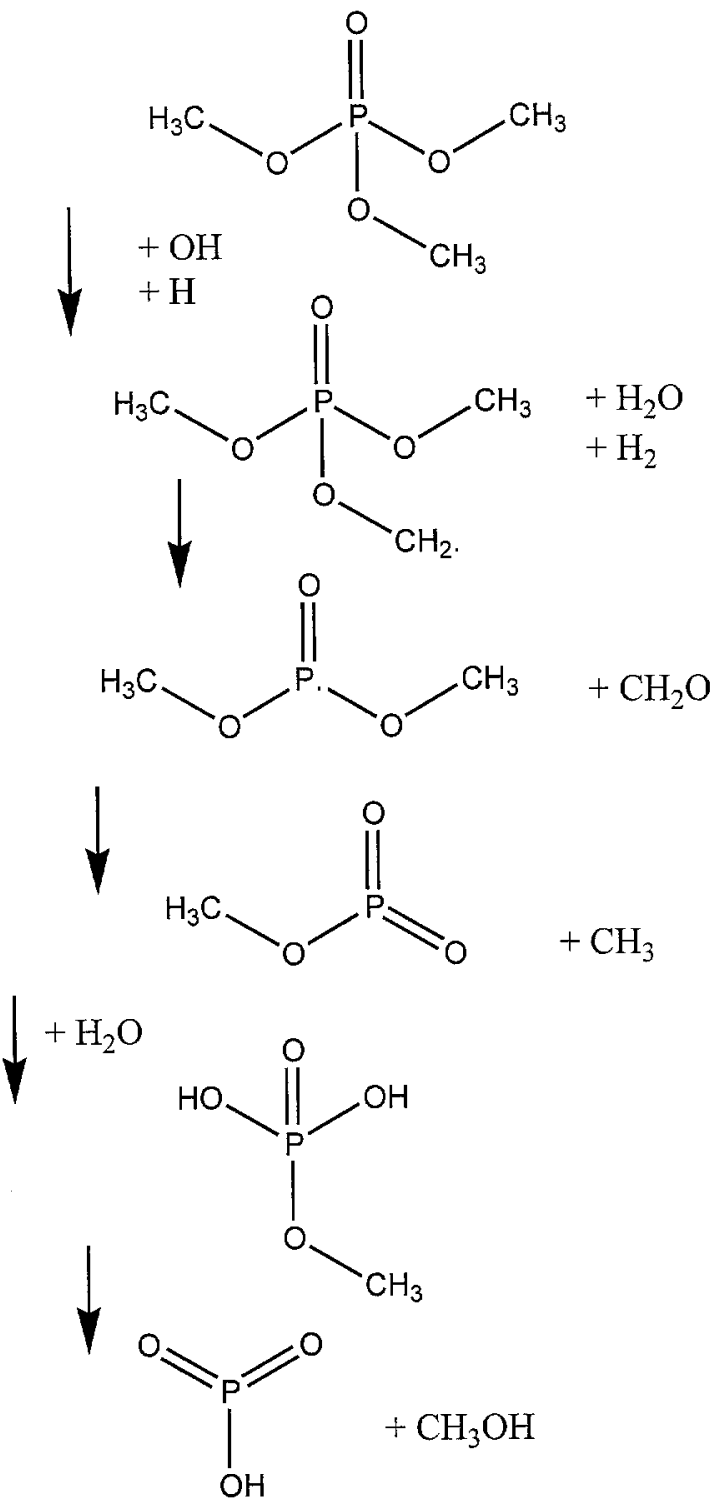

Figure 6: TMP reaction path 

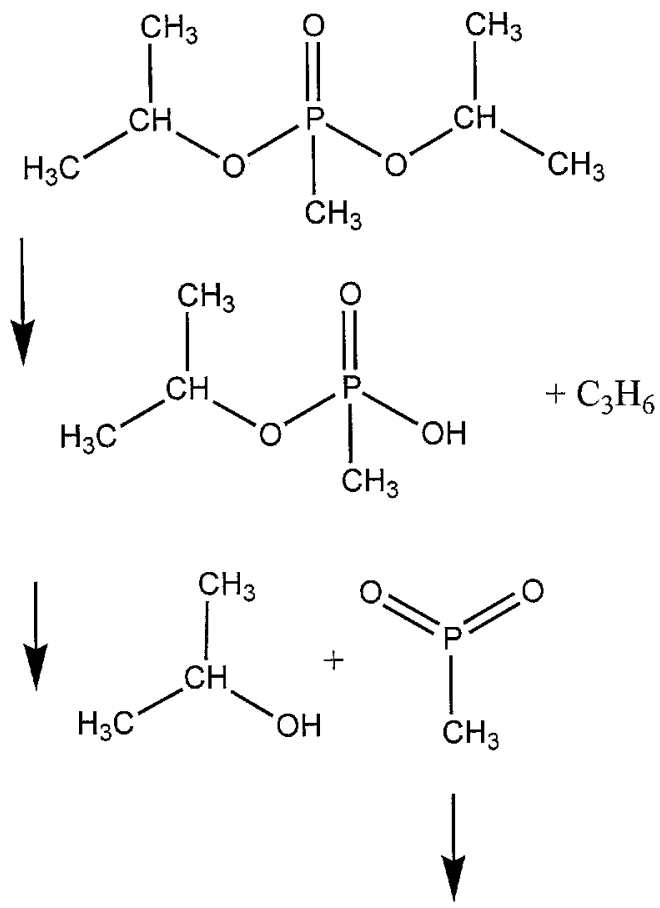

$$
\mathrm{PO}_{2}+\mathrm{CH}_{3}
$$

Figure 7: DIMP reaction path 

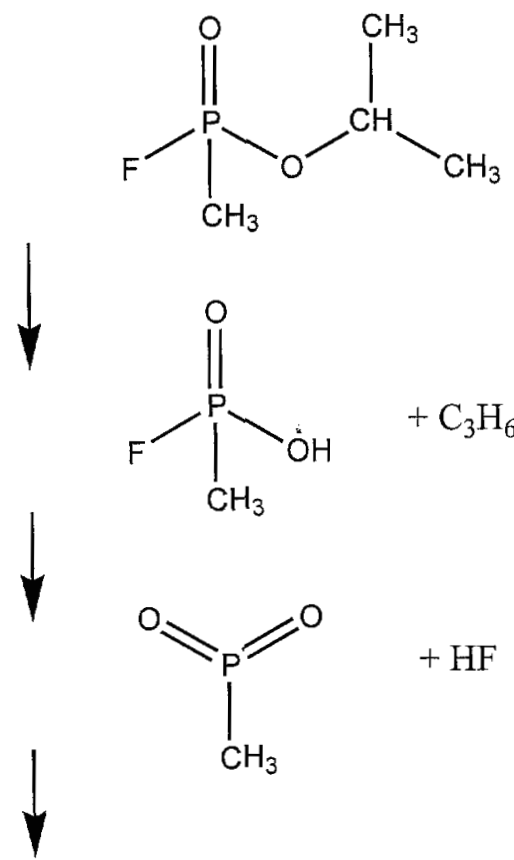

$\mathrm{PO}_{2}+\mathrm{CH}_{3}$

Figure 8: GB reaction path 